\title{
FAZER O MESMO, SEM SER O MESMO: FEMINILIDADES, NEOLIBERALISMO E ANTIFEMINISMO NO CONTEXTO GODLLYWOOD BRASIL
}

\author{
Monise Martinez* \\ (D) https: / / orcid.org/0000-0002-2324-9752
}

\section{Resumo}

Nas últimas duas décadas, processos políticos e sociais têm culminado, globalmente, numa hipervisibilização dos feminismos pautada numa dinâmica de ações e de reações a estes. A neoliberalização dos feminismos, notável na emergência de «subjetividades femininas» construídas a partir deles ao passo que os descontrói, no âmbito secular e religioso, tem corroborado esta conjuntura. Situando nesta dinâmica o programa disciplinar Godllywood Autoajuda, da Igreja Universal, no Brasil, neste artigo traçarei as relações entre as «feminilidades» propagadas por este visando examinar suas convergências com as neoliberais na sua relação com os feminismos através de uma análise do conteúdo, feminista e crítica dos discursos propagados na edição de 2018.

Palavras-chave: feminilidade; neoliberalismo; pós-feminismo; antifeminismo; Godllywood.

\begin{abstract}
Doing the same without being the same: Femininities, neoliberalism and antifeminism in the Godllywood Brazil context.

In the last two decades, political and social processes have culminated in a hyper-visibility of feminisms guided by global actions and reactions to them. The neoliberalization of feminisms, marked by «female subjectivities» built out of them while deconstructing them in both secular and religious fields, has corroborated this conjuncture. Setting the Brazilian Universal Church's Godllywood Self-help disciplinary program in this context, in this article I will analyze the relations between the «femininities» promoted by it and the neoliberal ones, calling attention to their connections to feminisms. For this purpose, a feminist critical content analysis of the speeches disseminated in the 2018 program edition will be carried out.
\end{abstract}

Keywords: femininity; neoliberalism; postfeminism; anti-feminism; Godllywood.

\section{Resumen}

Haciendo lo mismo, sin ser lo mismo: Godllywood, feminismos y las disputas por visibilidad en el Brasil contemporáneo.

Procesos políticos y sociales han contribuido para una hiper-visibilidad de los feminismos, a nivel global, en las últimas dos décadas. La neoliberalización de los feminismos ha corroborado esta coyuntura, como viene demostrando la emergencia de «subjetividades

Doutoranda em Estudos Feministas no Centro de Estudos Sociais, Univ Coimbra (CES/UC), 3000-104 Coimbra, Portugal.

Endereço postal: Centro de Estudos Sociais, Colégio de São Jerónimo, 3000-104 Coimbra, Portugal. Endereço eletrônico: martinezmonise@gmail.com 
femeninas» que se construyen desde ellos mientras los deshacen en el marco del secular y del religioso. Ubicando en esta dinámica el programa disciplinar Godllywood Autoayuda, de la Iglesia Universal, en Brasil, en este artigo identificaré las convergencias entre las «feminidades» impulsadas por el programa y las neoliberales en su relación con los feminismos desde un análisis del contenido, feminista y crítico de los discursos propagados en la edición 2018 del programa.

Palabras-clave: feminidad; neoliberalismo; postfeminismo; antifeminismo; Godllywood.

\section{Introdução}

Ao longo das últimas décadas, estudos sobre as relações entre os feminismos e o neoliberalismo têm destacado diferentes estratégias por meio das quais, seja enquanto um projeto político, uma doutrina econômica ou uma racionalidade, o neoliberalismo tem cooptado os feminismos (Prügl 2015). Categorizada, consoante o enfoque adotado, como feminismo de mercado e feminismo neoliberal, a expressão feminista derivada deste processo de neoliberalização tem sido examinada, no campo da comunicação e dos media, sob as lentes do pós-feminismo - termo sensivelmente usado para referir um fenômeno observado primeiramente na cultura mediática e pop no Norte global, a partir dos anos 1990, resultante das intersecções entre os media, a cultura de consumo, a política neoliberal e os feminismos (Genz e Brabon 2009).

Dentre as tendências comuns ao fenômeno, a emergência de subjetividades femininas tem sido um importante parâmetro para análise. Ao longo dos anos 2000, estudos sobre o tema evidenciaram uma dinâmica ambígua entre tais subjetividades e os feminismos na medida em que estas pareciam construir-se a partir deles ao passo que os descontruíam (McRobbie 2004; McRobbie e Ross 2011), bem como sistematizaram aspectos destas subjetividades atentando-se especialmente a gramática neoliberal que as atravessava, pautada nos credos da liberdade de escolha, transformação, autonomia feminina e disciplinarização dos corpos (Gill 2007; 2008; Gill e Scharff 2011). No Sul global, o conceito «pós-feminismo» tem sido usado em alguns estudos para destacar a existência de um regime de colonialidade de gênero no qual, na medida que tais subjetividades são difundidas como hegemônicas, adentram igualmente à vida cultural em realidades neoliberalizadas outras, como no caso da América Latina (Giraldo 2016).

Mudanças substanciais nas relações entre tais subjetividades e os feminismos têm sido notadas, contudo, na esteira de fatores múltiplos que têm corroborado, especialmente nesta última década, um momento de hipervisibilidade dos feminismos (Banet-Weiser, Gill, and Rottenberg 2020). Dentre os principais, é certo que os avanços nas agendas de gênero desde a IV Conferência Mundial da Mulher, em Pequim, em 1995, bem como o ciberfeminismo têm sido importantes para este efeito (Matos 2017). Junto deles, outros fatores relacionados têm sido notados, 
nomeadamente: o aumento de iniciativas neoliberalizadas que se reivindicam feministas alinhando-se, contraditoriamente, às forças sociais e culturais promotoras de iniquidades estruturais de gênero (Banet-Weiser, Gill e Rottenberg 2020); a proeminência de subjetividades femininas individualizadas, que invisibilizam e esvaziam o sentido político dos feminismos face as expressões engajadas (BanetWeiser, Gill e Rottenberg 2020); expansão e fortalecimento de reações antigênero por meio da direita conservadora a nível global (Corredor 2019); e a intensificação de reações misóginas na paisagem midiática ${ }^{1}$ (Banet-Weiser 2018).

Neste contexto, alguns estudos têm identificado a emergência de perfis de feminilidade delineados em conformidade com subjetividades neoliberais, em oposição aos feminismos, verificados em iniciativas corporativas e mediáticas associadas a grupos religiosos cristãos. Nos Estados Unidos, por exemplo, uma análise das narrativas de sucesso publicadas on-line por trabalhadoras de uma empresa ligada ao American Prosperity Gospel (APG) - movimento dissidente do Pentecostalismo, adepto da Teologia da Prosperidade (TP) e gerador de uma indústria de mídia e publicação (Bowler 2013) - destacou a existência de um perfil de «subjetividade pós-feminista evangélica» assente no reforço dos papéis tradicionais de gênero (Sullivan e Delaney 2016). No entanto, estudos mais detalhados sobre as convergências de fatores que sustentam estas subjetividades ainda são escassos, de maneira geral.

Visando contribuir para o desenvolvimento desta literatura, o presente artigo busca promover uma reflexão sobre o tema situando-o no contexto do Sul global, por meio de uma análise do ideário de feminilidade promovido pela Igreja Universal do Reino de Deus (IURD) - grupo neopentecostal, de afinidade teológica com o APG. No coração desta proposta, está a constatada proeminência que as questões relacionadas ao "gênero» e aos «feminismos» têm tido na esfera pública brasileira; o uso meta-político que se tem feito destas categorias nas disputas de narrativa na "paisagem midiática», marcada por uma forte presença de ações feministas e reações misóginas; e a hipótese de que, em tempos «pós-feministas», a IURD tem sido uma força importante na construção política de uma ideologia de gênero ${ }^{2}$ aliada ao conservadorismo de direita por meio da propagação de um ideário de feminilidade conhecidamente arraigado em papéis tradicionais de gênero, disseminado, no entanto, numa relação de oposição aos feminismos através de uma estratégica cooptação e esvaziamento político destes, além de estreitas relações com expressões neoliberalizadas.

Para o cumprimento do objetivo antes explicitado, este artigo será dividido em sete partes: a primeira consistirá numa leitura contextual das dinâmicas de

Cf. Banet-Weiser (2018), um contexto econômico e tecnológico de visibilidade em que expressões do feminismo e a misoginia disputam pela hegemonia de significados.

2

Neste contexto, «ideologia de gênero» é usado para referir crenças estruturadas e ideias sobre construções sociais associadas aos corpos sexuados. 
polarização e ambiguidades em torno dos feminismos na paisagem política e midiática brasileira; a segunda incide sobre a emergência de um grupo seleto de mulheres da IURD nas mídias da Igreja na sua relação com o surgimento de um projeto disciplinar voltado para mulheres chamado Godllywood, em 2010, atentando-se à modalidade on-line «Autoajuda»; a terceira é dedicada à apresentação do corpus e da metodologia de trabalho na identificação do ideário de feminilidade proposto pela Igreja, bem como das estratégias retóricas usadas na sua construção; a quarta, quinta e sexta partes apresentam a análise qualitativa do material selecionado; a sétima, enfim, discute os contributos deste trabalho.

\section{Da política institucional à paisagem midiática: polarização, feminismos e conservadorismos}

O neoliberalismo e os posicionamentos contrários a um projeto feminista de sociedade têm sido apontados como denominadores comuns no espectro da direita conservadora a nível global (Norocel 2018). Dentre as estratégias adotadas na construção das narrativas neste meio, está a disseminação da «ideologia de gênero» - um projeto político articulado pela Santa Sé, especialmente após Pequim, com vistas a conter os supostos «perigos» da perspectiva construcionista de gênero defendida por delegadas feministas na ocasião, bem como os avanços e visibilidade paulatina de suas bandeiras e das LGBTQ+ desde então (Machado 2018; Corrêa e Kalil 2020). Convergindo com os interesses econômicos comuns no conservadorismo de direita, o qual, ao defender a «família tradicional» baseando-se numa hierarquia complementar sustentada teológica e biologicamente entre o masculino e o feminino, reforça a ordem patriarcal (Norocel 2018), a narrativa do combate à «ideologia de gênero» tem sido uma das principais linhas de força adotadas por representantes populistas do espectro, como o caso Bolsonaro no Brasil (Payne e Santos 2020).

$\mathrm{Na}$ arena da política institucional do país, parte substancial dos embates polarizados que tomaram as redes e as ruas em 2018 tiveram início em 2003, no primeiro mandato de Lula, quando as primeiras polêmicas relacionadas à adoção da perspectiva construcionista sobre «gênero» nas políticas públicas e os avanços das agendas em torno dos direitos reprodutivos e da sexualidade emergiram no Congresso Nacional (Machado 2018). Contudo, é certo que a retórica da «ideologia de gênero» adquiriu maior corpulência no país a partir de 2008, na esteira de uma emblemática visita de Ratzinger, da assinatura de um acordo entre a Santa Sé e o Estado brasileiro em torno das ações da Igreja Católica no país e, enfim, da consolidação de um campo de obras e publicações antigênero (Corrêa e Kalil 2020). Neste processo de disseminação, a retórica ganhou especial impulso no Congresso em 2010, quando católicos e evangélicos uniram esforços dentro e fora da política institucional em prol da retirada dos termos «gênero» e «orientação sexual» do 
Plano Nacional de Educação (PNE) inaugurando uma nova fase de reações de parlamentares antigênero.

Paralelamente a este quadro legislativo, a emergência de uma nova estrutura nos media sociais contribuiria, na paisagem midiática brasileira, para uma intensificação das batalhas por hegemonia de discursos a partir de 2013, quando a polarização entre forças feministas, LGBTQ+ antirracista e, no contraponto, conservadora tornou-se mais evidente on-line. Naquele ano, manifestações com reivindicações plurais e consoante diferentes contextos tomaram as ruas de diversas partes do país, adentrando no espectro dos emblemáticos atos que tiveram lugar a partir de junho, quando tiveram início ações encabeçadas pelo Movimento Passe Livre (MPL) contra o aumento das tarifas do transporte público em São Paulo (Pinheiro-Machado 2019). Apoiadas pela grande mídia após um violento episódio de repressão policial no ato do dia 13 de junho, uma nova face das manifestações emergiu com agendas difusas e apropriadas pela direita, pautadas em narrativas de vilanização de movimentos como os feministas, LGBTQ+ e antirracistas, bem como do PT, das esquerdas, do comunismo e da ONU (Pinheiro-Machado 2019; Corrêa e Kalil 2020).

O momento de convulsão política impulsionado pelas «Jornadas de Junho» foi propiciado, contudo, por fatores precedentes de ordem diversa que culminaram naquele momento. No que respeita ao uso das redes, por exemplo, é importante destacar que blogues, perfis e sites feministas estavam em ascensão desde meados dos anos 2000, e foram impulsores cruciais para o ativismo e a visibilidade dada aos feminismos no contexto brasileiro ao operar como ferramentas na expansão do movimento (Ferreira 2015; Matos 2017). Junto deste fortalecimento, contudo, expressões neoliberalizadas também foram ganhando forças, e organizações católicas e evangélicas faziam uso das redes para disseminar a narrativa da «ideologia de gênero», a qual é antifeminista per se (Corrêa e Kalil 2020). Com o estabelecimento de novas tendências on-line a partir de 2013, os embates entre estas expressões se acirraram. Assim, ao mesmo tempo que manifestações significativas e campanhas on-line culminavam na «Primavera das Mulheres», em 2015 (Reis 2017), e os feminismos apareciam nos anúncios televisivos, debates nas redes sociais e no mercado editorial, reações antifeministas eram promovidas por celebridades e movimentos de direita on-line, como o Movimento Brasil Livre (MBL) (Ferreira 2019); vídeos disseminados por pastores evangélicos sobre a «ideologia de gênero» eram amplamente difundidos; e materiais sobre o tema produzidos por grupos de cristãos conservadores eram distribuídos em todo o país (Machado 2018).

Neste cenário de polarização, mulheres desempenharam - e têm desempenhado - papéis cruciais no fortalecimento de ações antifeministas. Nos bastidores do Congresso Nacional, por exemplo, a participação de católicas e pentecostais serviu para sublinhar a existência de ativistas que, sem se identificarem como feministas, diziam-se comprometidas com os direitos das mulheres e contrárias à 
«ideologia de gênero» (Machado 2018). Nas redes, iniciativas de grupos de direita davam protagonismo a mulheres antifeministas, como Sara Giromini, que organizou o I Congresso Antifeminista Brasileiro em 2018 (Ferreira e Silva 2019). Nos media religiosos, pastoras e esposas de pastores evangélicos frente à audiência feminina com vistas a fomentar «modelos de feminilidade» tradicionais cumpriam igualmente um importante papel neste cenário usando suas redes pessoais ou canais institucionais das Igrejas (Machado 2018), como o caso de Cristiane Cardoso, da IURD, que tem apresentado uma performance «transreligiosa» (Campos e Souza 2017), ancorada numa gramática «pós-feminista», combatendo agendas feministas especialmente por meio de iniciativas ligadas ao Godllywood (Martinez 2018).

\section{Resposta «Universal»: mídia, mulheres e a criação do Godllywood}

A IURD foi fundada em 1977, por Edir Macedo, no Rio de Janeiro. É uma Igreja neopentecostal, adepta da Teologia da Prosperidade (TP) originariamente difundida pelo American Prosperity Gospel (APG) e, por isso, fundamentada na crença de que cumprindo um estrito percurso de fé, fiéis logram alcançar riqueza, saúde e vitória. Desde a sua fundação, caracterizada pelo uso massivo dos meios de comunicação, do rádio às novas mídias, a Igreja foi considerada uma peça-chave para mudanças significativas no campo religioso brasileiro na sua relação com o campo político (Martino 2017, 41-46). Da participação na fundação da Frente Parlamentar Evangélica, em 1986, à compra da Rede Record, em 1989, à criação do Partido Republicano Brasileiro (PRB), em 2005, e à eleição de 106 prefeitos pela sigla em 2016, a atuação política estruturada da IURD tem sido substancialmente permeada pelo uso que faz de suas mídias religiosas (Suruagy apud Dip 2018).

Em seu contexto de atuação midiática, o enfoque em temas relacionados às mulheres, bem como a presença destas nas atividades da Igreja nas mídias eletrônicas e impressas teve início no fim dos anos 1990 (Machado 1999, 184). Seguindo as tendências de incorporação de pautas dirigidas à audiência feminina e de contratação de mulheres nas mídias «seculares», esposas de bispos e pastores entraram em cena para abordar temas relacionados à saúde feminina na programação radiofônica, e também na televisiva, onde atendiam e aconselhavam pessoas, especialmente mulheres, legitimando as opiniões antes emitidas por seus maridos (Machado 1999, 171-175). Com a popularização das mídias digitais no início dos anos 2000, a participação das mulheres nas mídias do Grupo Universal foi intensificada, marcada por sua atuação em blogues e redes sociais. Entre as que ganharam maior visibilidade neste contexto, está Cristiane Cardoso, filha primogênita de Edir Macedo, desde 2007 autora de best-sellers e principal representante do Godllywood. 
O projeto Godllywood foi concebido por Cardoso e Evelyn Higginbotham, em 2009, em Houston, nos Estados Unidos, tendo como principal objetivo tornar jovens fiéis da Igreja «melhores para Deus» à base de um programa disciplinar articulado em torno de reuniões de grupo e do cumprimento de tarefas prescritas por mentoras nomeadas Big Sisters. ${ }^{3}$ Implementado no Brasil no ano de 2010, o projeto foi apresentado com vistas a combater «valores errados» promovidos por Hollywood através do resgate de uma suposta «essência feminina» prescrita por Deus $^{4}$ num momento em que os discursos antigênero ganhavam força no país, plataformas feministas on-line despontavam e o Censo revelava que as mulheres eram a maioria entre a população evangélica.

Inicialmente operacionalizado em templos de capitais brasileiras e restrito a grupos seletos de frequentadoras da Igreja, o projeto atendia um público feminino em diferentes faixas etárias, era facilitado por esposas de bispos e pastores, representado em seu máximo por Cardoso e dinamizado através do cumprimento de «desafios»: tarefas diárias que, sistematizadas num calendário semanal, culminavam na produção de pequenas narrativas de êxito a serem partilhadas pelas integrantes adolescentes e adultas na página do projeto no Facebook (Teixeira 2014, 237-238). Em 2011, quando o ativismo feminista on-line ganhava forças, culminando na organização de atos como a primeira Marcha das Vadias no Brasil, a primeira modalidade on-line do programa, nomeada Desafio Godllywood, foi implementada atendendo a demandas de mulheres da IURD em cidades e países outros (Teixeira 2014, 248-249). Em dezembro de 2015, ano da já referida «Primavera das Mulheres», uma versão estendida a toda e qualquer mulher interessada em participar da dinâmica foi lançada: o Godllywood Autoajuda.

Como na versão do programa in loco, tal modalidade foi construída em torno de um percurso de aprimoramento pessoal focado na performance da «mulher virtuosa». Perfil apresentado em minúcia por Cristiane Cardoso no best-seller Mulher V: Moderna à moda antiga (2011), publicado um ano após a implementação do Godllywood no Brasil, a «Mulher V» consiste numa versão repaginada do modelo de feminilidade introduzido por Macedo em O perfil da mulher de Deus (1992), tendo sido inspirado no livro The Total Woman (1973), de Marabel Morgan (Teixeira 2012). Buscando tecer um diálogo mais próximo com o público feminino, o best-seller de Cardoso reivindica o lugar da experiência de quem o escreve: uma mulher que logrou ter sucesso no casamento, na família, no trabalho e na vida espiritual, e que partilha seus ensinamentos com as demais apresentando-se como um exemplo. À parte disto, valendo-se de uma linguagem mais próxima do «secular», o best-seller é também construído a partir de narrativas comuns à literatura de

Informações disponíveis em: http://redealeluia.com.br/odllywood-o-resgate-da-essencia-femininal. Acesso em 24 de outubro de 2020.

4 Informações disponíveis em: https://instagram.com/tv/B74QIC8gEPb/?hl=pt. Acesso em 24 de outubro de 2020. 
autoajuda - a qual está arraigada em elementos míticos da cultura popular norte-americana -, introduzindo o ideário da Mulher $V$ numa relação de oposição a modelos de feminilidade que julga «hegemônicos», nocivos às mulheres e relacionados ao que entendem, de modo geral, como feminismo (Martinez 2018).

Tendo o referido modelo de feminilidade como base de sua estrutura basilar, a modalidade Autoajuda foi operacionalizada, entre os anos de 2016 e 2018, usando o blogue oficial do projeto como principal ferramenta. Por meio de posts com tarefas publicadas semanalmente durante um período específico do ano por Cristiane Cardoso, o programa apresentava-se como uma proposta de «transformação» voltada para mulheres estruturando-se a partir de três componentes: uma diretiva, executada por Cardoso, que informava, nos posts, o quê, como e por quê deveria ser feito; uma tutelar, administrada pelas esposas de pastoras nos templos, em reuniões mensais in loco, e/ou pela figura da «amiga como irmã», uma mulher escolhida pela própria participante para acompanhá-la em sua jornada incentivando-a; e a de auto-gestão, administrada pelas participantes. As «tarefas como oferta» organizavam-se em torno de práticas de ação direta e de autorreflexão, sobre temas como a espiritualidade, a feminilidade e os cuidados com o corpo e com a mente, e eram eventualmente partilhadas pelas participantes nos comentários do blogue ou em suas redes sociais, com uso de hashtags, à parte da recomendação de serem registradas num diário. Por meio desta dinâmica, a expectativa era a de que as mulheres incorporassem um perfil determinado de subjetividade feminina e cristã, ancorada nos papéis tradicionais de gênero, mas apresentadas, contudo, a partir de uma estética mais «secularizada» a fim de ampliar a sua visibilidade na paisagem midiática brasileira.

A partir de 2019, a modalidade passou a ser operacionalizada de modo mais centralizado por meio de perfis no Instagram e no Youtube, tendo o Godllywood alcançado o status de «movimento»: uma mudança apresentada na página oficial do programa como necessária para expandir a iniciativa entre mulheres interessadas em «viver segundo os princípios e conceitos» do programa. Apresentado como um movimento «sem ideologia», a iniciativa identifica-se como um «movimento de mulheres diferente do 'feminista'», propondo-se de forma mais ou menos indireta, como uma alternativa a este por meio da propagação do modelo de Mulher $V$, a qual, tendo-se em conta os já referidos contextos de polarização em torno de "gênero» e «feminismo» no Brasil das últimas décadas, tem sido construído numa relação de oposição estratégica aos feminismos. Apresenta, no entanto, estreitas relações com expressões neoliberalizadas enquanto resposta aos avanços e alta visibilidade por eles adquiridos, bem como sua relevância na conjuntura de disputas políticas no Brasil e a nível global. 


\section{Metodologia}

Tendo em vista o objetivo central deste artigo, foram selecionados para a análise vinte posts de autoria de Cardoso no blogue oficial do Godllywood entre fevereiro e março de $2018,{ }^{5}$ no âmbito da edição Autoajuda do referido ano. A escolha deste material deu-se em função de três razões: o fato de constituir a última edição em que blogue fora usado como principal ferramenta para a realização do programa em larga escala; a última antes do Godllywood ser declarado como um «movimento»; e, enfim, num período acirrado de disputas de narrativas em torno das questões de «gênero», como já dito, marcado pelas eleições presidenciais que teriam lugar em outubro daquele ano.

Usando primeiramente como metodologia a análise de conteúdo (Bardin 2011), a unidade de análise determinada durante a fase de codificação do material foi a das recomendações em tom imperativo e/ou de conselho dadas às participantes do programa a cada tarefa. De seguida, após uma segunda leitura dos excertos antes codificados, duas categorias temáticas de análise foram determinadas tendo-se em conta a noção de «sensibilidade pós-feminista» cunhada por Gill (2007) para enfatizar «a natureza contraditória dos discursos pós-feministas e as relações entre os temas feministas e antifeministas dentro deles» (151) e a compreensão do feminismo de acordo com a definição mínima de hooks (1984: 26) enquanto «luta pelo fim da opressão sexista»: $a$. a cooptação do feminismo por meio de aproximações estratégicas da retórica de suas expressões neoliberalizadas; e $b$. subversão do feminismo por meio de sua vilanização e/ou difamação.

Sob estas categorias, três tendências recorrentes foram encontradas nos posts analisados: mente, na qual foram agrupados excertos construídos a partir de imperativos sobre temas como «autoconfiança», «autoestima» e «positividade»; corpo, constituída por excertos sobre os cuidados com a aparência; e comportamento feminino, na qual se encontram as prescrições relacionadas precisamente com a ideia de feminilidade. Para a interpretação de tais excertos, uma análise crítica e feminista do discurso (Lazar 2007) foi realizada com vistas a compreender «como a ideologia de gênero e as relações de poder em torno do gênero são (re)produzidas, negociadas e contestadas nas representações de práticas sociais» (150).

Nos tópicos a seguir, a análise focada nas estruturas argumentativas, escolhas lexicais e padrões de enunciados no corpus será apresentada consoante cada um dos padrões pré-determinados.

Todas as tarefas da edição Autoajuda 2018 estão disponíveis no link: https://universal.org/godlly wood/auto-ajuda/. Acesso em 12 de julho de 2020. 


\section{Feminilidade e mente}

O paradigma de transformação pessoal tornou-se um elemento central na cultura pós-feminista (Gill 2017). Especialmente popularizado na cultura midiática e popular dos anos 1990 e 2000 por meio de propostas disciplinares que propunham-se a resolver dilemas da vida física, afetiva e psicológica de mulheres, as lógicas deste paradigma foram revitalizadas à medida que o processo de neoliberalização dos feminismos avançou, acomodando-se cada vez mais ao credo individualizado no «empoderamento feminino» em torno de mantras relacionados à autoconfiança, à positividade, à autoestima e à resiliência - «novos» elementos de sucesso feminino (Gill 2017).

Nas tarefas propagadas no âmbito do Autoajuda 2018, a gramática «secular» que envolve estes mantras foi adaptada à cosmovisão neopentecostal - a qual entende o sucesso como a prova de que o indivíduo está em dia com a sua fé. Assim, apresentados e incentivados no programa por meio de práticas que têm como maior propósito «agradar a Deus», os mantras da autoconfiança e da autoestima, por exemplo, são tomados como sinais de que as mulheres estão cumprindo com o propósito do programa, como exemplifica o fragmento extraído de uma tarefa centrada na questão da proatividade:

Ficar adiando a sua vida é um sinal de baixa autoestima, insegurança, irresponsabilidade, preguiça, fraqueza, dúvida, confusão, depressão, desorganização e, consequentemente, NÃO SER DE DEUS. Repare o quanto você se sente longe de Deus quando se descuida e deixa o tempo escapar por entre os dedos.

A Tarefa como Oferta 16 é para você fazer o que Deus faz: controle o seu tempo, tenha disciplina, e nunca mais deixe que algo atrase a sua vida - seja preguiça, lentidão ou distração. Em outras palavras: trabalhe duro. (Cardoso 2018, Tarefa 16)

Como demonstra o fragmento, o processo disciplinar de transformação godllywoodiano é atravessado por uma ideia de gestão e controle de demandas mentais com vistas a eficiência, também reforçadas em várias ações por meio das quais as mulheres são incentivadas a se tornarem as melhores no que fazem (ver Tarefas 13 e 14). À semelhança dos discursos pós-feministas sobre as práticas de transformação, no programa estas premissas corroboram a responsabilização das participantes pelo seu bem-estar psicológico, reduzindo problemas como a depressão e insegurança a uma escolha pessoal. Invisibilizando desigualdades estruturais, a solução foca-se no fomento de ações individuais como «orar» e «ser positiva», sendo constantemente reforçada por Cardoso assente na fórmula do sucesso que define, também, as subjetividades feministas neoliberalizadas:

Depois que entramos no mercado de trabalho e adquirimos os direitos iguais aos dos homens, a simplicidade de ser mulher se tornou uma verdadeira complexidade! 
Temos que dar conta de tudo e não deixar nada a desejar, senão dizem que é porque somos mulher. (Cardoso 2018, Tarefa 15)

No entanto, e como demonstra o fragmento, diferente do sujeito que se reivindica como feminista ao "glamorizar» a sobrecarga que recai sobre as mulheres por meio da valorização de iniciativas criativas e empreendedoras para gerir o tema (Rottenberg 2018, 36-39), o programa invoca a mesma estrutura para culpabilizar o feminismo por este feito, como denota a ideia negativa de «complexificação» da vida de mulheres atrelada às menções sobre a entrada destas no mercado de trabalho e aos «direitos iguais», isto é, bandeiras históricas do movimento feminista dos anos 1970 .

\section{Feminilidade e corpo}

O corpo feminino é também um aspecto central da cultura pós-feminista (Gill 2017). Representado como um elemento definidor da feminilidade na cultura popular e mediática das décadas de 1990 e 2000, àquela época o corpo era reivindicado como uma «fonte de poder feminino» estabelecendo uma relação ambígua com os feminismos: ao passo que simbolizava um espaço de ressignificação positiva da ideia de «feminino», tornava-se foco de práticas de monitoramento e disciplina que delineavam novos padrões de atratividade em torno de temas como liberdade sexual, escolha e empoderamento (Gill 2007). No cenário de intensificação da visibilidade e neoliberalização dos feminismos, o corpo se tornou, também, um outdoor do feminismo enquanto mercadoria, servindo, no que respeita o caso estudado, também como um outdoor do modelo cristão goodllywoodiano.

No âmbito das tarefas do Autoajuda 2018, prescrições estritas relacionadas aos cuidados com a aparência foram apresentadas, tal qual aquelas relacionadas à mente, como formas de «agradar a Deus», como o excerto de uma tarefa dedicada ao tema da «discrição feminina» bem exemplifica:

Naquela época, as mulheres que vestiam de forma sensual diziam «eu sou prostituta.» Mas hoje, que a moda dita que a mulher deve se vestir de forma sensual, o que ela diz? O que ela quer? Quem ela quer chamar atenção e para quê?

[...] Você vai vestir o que vai glorificar o Seu Senhor neste próximo domingo. Você vai usar saia ou vestido, num comprimento perfeitamente discreto (nada de minissaia ou saia curta) e confortável, sem marcar nenhuma parte íntima, nada colado, nem transparente, pois a atenção que você quer não é dos homens e sim a do seu Senhor. E assim falar para Ele, através do seu vestir, o quanto você aprecia ter nascido mulher, que pode ser feminina sem precisar se igualar ao homem para ter valor nem direitos, e que não precisa usar o seu corpo para se sentir valorizada. (Cardoso 2018, Tarefa 5) 
No fragmento, a ideia de «valorização» do feminino circunscrita ao corpo perpassa, como na cultura pós-feminista, por um propósito de ressignificação do feminino, tal qual o ato de se mostrar a Deus o apreço por «ter nascido mulher» evidencia. Como denota o diálogo implícito entre a forma de apresentar este propósito e a máxima de Simone de Beauvoir, em O Segundo Sexo (1949), esta «ressignificação do feminino» é neste contexto realizada a partir de uma concepção biologista do gênero; de um entendimento desvirtuado do feminismo comumente referido nas falas de Cardoso e que, no caso do fragmento, se explicita pela ideia de que este é um movimento que reivindica o direito e o valor das mulheres enquanto sujeitos literalmente iguais aos homens; e de uma nítida relação de oposição entre o modelo «virtuoso» que propõe um modelo estereotipado da mulher feminista como a que «usa» o corpo para se sentir valorizada, deslegitimando, assim, a reivindicação da sexualidade feminina a ele atrelada.

\section{Feminilidade e comportamento}

A oposição entre o perfil de mulher godllywoodiano e o creditado como feminista no âmbito do programa é evidenciado, sobretudo, nas recomendações de ordem comportamental associadas à «performance feminina» ensejada no programa. No coração deste diagnóstico, está o fato de que, tal qual o modelo de mulher bem-sucedida que logra equilibrar carreira, família e lar é promovido como «empoderado» e «feminista» (Rottenberg 2018), o modelo Godllywood pauta-se pela neutralização das mesmas desigualdades de gênero que constituem a vida desta mulher multitarefas apresentando-a como «forte» e desejável aos olhos de Deus. Junto desta performance de sucesso, as mulheres são incentivadas a investir no seu «lado feminino»e, consoante a distorcida concepção de feminismo propagada no programa, a se afastarem do perfil «feminista» sendo "graciosas», «cuidadosas» e «maleáveis» - características apresentadas por Cardoso como opostas à ideia de «fraqueza» atribuída ao feminino e, por esta razão, rechaçadas por um suposto discurso mainstream de que as mulheres «devem ser iguais aos homens» (ver Tarefa 11).

Assente em prescrições de gênero biologistas, hierárquicas e patriarcais que acompanham o Pentecostalismo desde as suas origens e tornaram-se significativamente mais rígidas para as mulheres das Igrejas quando as leituras fundamentalistas-literalistas foram popularizadas no movimento, a ideia de "ser feminina» também se acomoda a domesticidade. Apresentada no âmbito do programa por meio de uma estética glamorizada que tem permeado igualmente a cultura popular pós-feminista sob o credo da «livre escolha», a domesticidade é o tema, por exemplo, numa tarefa em que, após as participantes serem incumbidas de limpar e organizar o lar, Cardoso finaliza o post com um comentário em que valoriza esta prática desafiando quem a problematiza: 
Depois de tudo arrumadinho, tire umas fotos e cole no seu diário para você lembrar dos momentos logo após toda essa arrumação... se você é como eu, vai fazer questão de antes de sair pela porta, dar mais uma olhadinha para traz (sic), suspirar profundamente e se alegrar de ter um cantinho tão gostoso de viver! [...]

Você vai ver como é bom aquilo que dizem ser tão degradante! (Cardoso 2018, Tarefa 8)

Para além da domesticidade, a submissão é também um tópico recorrente nas tarefas analisadas, tendo sido especialmente trabalhado naquelas em que as participantes são convocadas a deixarem de ser «orgulhosas» praticando ações como «submeter-se a seus maridos», não ter a pretensão de serem independentes, nem de emitirem suas opiniões sobre quaisquer assuntos (ver Tarefas 9 e 10). Nestas tarefas, assim como no fragmento anteriormente citado e nas demais nas quais o tema do comportamento associado à ideia de feminino são retomadas, a performance godllywoodiana é sempre apresentada de maneira assertiva, glamourizada, e em oposição à que é considerada feminista e identificada - e também distorcida - ao longo de todo programa (e além dele) por meio de referências mais ou menos explícitas ao movimento, suas lutas e agentes.

\section{Considerações finais}

Como revelou a análise do corpus selecionado para este artigo, o modelo de feminilidade tal como vem sendo apresentado pela IURD na última década aproxima-se dos credos que têm atravessado as «subjetividades neoliberais», apresentando soluções individualizadas para problemas estruturais de gênero. As relações traçadas com os feminismos a partir deste paradigma são, no entanto, de oposição, diferenciando-se, neste sentido, das expressões neoliberalizadas que, na sua contradição, pretendem reivindicá-los. No âmbito do Godllywood, como destacado na análise, os feminismos e seus agentes são invocados como antagonistas ao perfil de mulher idealizado pela Igreja, o qual, vale ressaltar, é fruto de uma construção social teologicamente justificada no contexto do Pentecostalismo - e de outras religiões de matriz cristã - desde os seus primórdios.

Acompanhando o crescente das dinâmicas polarizadas, marcadas pelo paradigma de ações e reações em torno dos debates sobre «gênero» e «feminismo» no Brasil, as retóricas empregadas na promoção do tradicional modelo de feminilidade propagado pela Igreja, como evidenciado, aproximaram-se estrategicamente das expressões neoliberalizadas dos feminismos nas disputas que têm marcado a política institucional e a paisagem midiática brasileira em torno do tema. Reproduzindo, desta feita, uma dinâmica de cooptação e esvaziamento político, tornam-se uma importante ferramenta meta-política nas disputas pelo senso comune, aliando-se às forças conservadoras na manutenção conveniente do status quo por meio de uma ideologia de gênero que serve política e economicamente à 
ordem patriarcal. Neste sentido, e no contexto referido, a retórica opera como antifeminista, podendo ser compreendida, como as coincidências entre o seu processo de emergência e adaptação evidenciaram, como parte do conjunto diversificado de reações antigênero no cenário da política nacional.

\section{Referências bibliográficas}

Banet-Weiser, Sarah. 2018. Empowered: Popular Feminism and Popular Misogyny. Durham: Duke Univeristy Press.

Banet-Weiser, Sarah, Rosalind Gill e Catherine Rottenberg. 2020. «Postfeminism, Popular Feminism and Neoliberal Feminism? Sarah Banet-Weiser, Rosalind Gill and Catherine Rottenberg in Conversation.» Feminist Theory 21(1): 3-24. DOI: https: / / doi.org/10.11 $77 / 1464700119842555$.

Bardin, Laurence. 2011. Análise de Conteúdo. Coimbra: Edições 70.

Bowler, Kate. 2013. Blessed: A History of the American Prosperity Gospel. New York: Oxford University Press.

Campos, Roberta Bivar Carneiro, e Alana Souza. 2017. «Godllywood de Cristiane Cardoso: uma etnografia do 'transreligioso'.» Revista de Antropologia 60(2): 487-512. DOI: http: / / dx.doi.org/10.11606/2179-0892.ra.2017.137318.

Corrêa, Sonia, e Isabela Kalil. 2020. Politicas Antigénero en América Latina: Brasil - ¿La Catástrofe Perfecta? Rio de Janeiro: Sexuality Policy Watch (SPW).

Corredor, Elizabeth S. 2019. «Unpacking 'Gender Ideology' and the Global Right's Antigender Countermovement.» Signs 44(3): 613-38. DOI: https: / / doi.org/10.1086/ 701171.

Dip, Andrea. 2018. Em nome de quem? A bancada evangélica e o seu projeto de poder. Rio de Janeiro: Civilização Brasileira.

Ferreira, Carolina Branco de Castro. 2015. «Feminism on the Web: Lines and Forms of Action in Contemporary Feminist Debate.» Cadernos Pagu 44: 199-228.

Ferreira, Isabelle Azevedo. 2019. «A ação política contra o feminismo: uma análise a partir do Movimento Brasil Livre (MBL).» In $42^{\circ}$ Congresso Brasileiro de Ciências da Comunicação, Belém, 2 a 7/09/2019, 1-15.

Ferreira, Salomé Margot Melo, e Edil Ferreira Silva. 2019. «'Não nos representam!': da crise de legitimidade feminista no discurso de mulheres do Movimento Brasil Livre MBL.» Caderno Espaço Feminino 32(2): 23-48. DOI: http: / / dx.doi.org/10.14393/CEF-v 32n2-2019-2.

Genz, Stephanie, e Benjamin A. Brabon. 2009. Posfeminism: Cultural Texts and Theories. Edinburgh: Edinburgh University Press.

Gill, Rosalind. 2007. «Postfeminist Media Culture: Elements of a Sensibility.» European Journal of Cultural Studies 10(2): 147-66. DOI: https: / / doi.org/10.1177/1367549407075898.

Gill, Rosalind. 2008. "Culture and Subjectivity in Neoliberal and Postfeminist Times.» Subjectivity 25(1): 432-45. DOI: https:/ / doi.org/10.1057/ sub.2008.28.

Gill, Rosalind. 2017. «The Affective, Cultural and Psychic Life of Postfeminism: A Postfeminist Sensibility 10 Years On.» European Journal of Cultural Studies 20(6): 606-26. DOI: https: / / doi.org/10.1177 / 1367549417733003.

Gill, Rosalind, e Christina Scharff. 2011. «Introduction.» In New Femininities: Postfeminism, Neoliberalism and Subjectivity, organizado por Rosalind Gill e Christina Scharff, 1-18. London: Palgrave Macmillan. 
Giraldo, Isis. 2016. «Coloniality at Work: Decolonial Critique and the Postfeminist Regime.» Feminist Theory 17(2): 157-73.

hooks, bell. 1984. Feminist Theory: From Margin to Center. Boston: South End Press.

Lazar, Michelle M. 2007. «Feminist Critical Discourse Analysis: Articulating a Feminist Discourse.» Critical Discourse Studies 4(2): 141-64. DOI: https://doi.org/10.1080/174059 00701464816.

Machado, Maria das Dores Campos. 1999. «SOS Mulher - a identidade feminina na mídia pentecostal.» Ciencias Sociales e Religión 1(1): 167-88.

Machado, Maria das Dores Campos. 2018. «O discurso cristão sobre a 'ideologia de gênero'.» Revista Estudos Feministas 26(2): 1-18. DOI: https://doi.org/10.1590/1806-9584-2018v 26 n247463.

Martinez, Monise. 2018. «Pós-Feminismo no Reino de Deus: reflexões sobre as ambiguidades de um percurso 'virtuoso'.» Cabo dos Trabalhos 17. https://cabodostrabalhos.ces. uc.pt/n17/ensaios.php.

Martino, Luís Mauro Sá. 2017. Mídia, Religião e Sociedade: das palavras às redes digitais. São Paulo: Paulinas.

Matos, Carolina. 2017. «New Brazilian Feminisms and Online Networks: Cyberfeminism, Protest and the Female 'Arab Spring'.» International Sociology 32(3): 417-34. DOI: https:// doi.org/10.1177/0268580917694971.

McRobbie, Angela. 2004. «Post-Feminism and Popular Culture.» Feminist Media Studies 4(3): 255-64. DOI: https://doi.org/10.1080/1468077042000309937.

McRobbie, Angela, e Jonathan Ross. 2011. «Beyond Post-Feminism.» Public Policy Research 18(3): 179-84.

Norocel, Ov Cristian. 2018. «Antifeminist and 'Truly Liberated': Conservative Performances of Gender by Women Politicians in Hungary and Romania.» Politics and Governance 6(3): 43-54. DOI: https://doi.org/10.17645/pag.v6i3.1417.

Payne, Leigh A., e Andreza Aruska de Souza Santos. 2020. «The Right-Wing Backlash in Brazil and Beyond.» Politics and Gender 16(1): 32-38.

Pinheiro-Machado, Rosana. 2019. Amanhã vai ser maior: o que aconteceu com o Brasil e possíveis rotas de fuga para a crise atual. São Paulo: Planeta.

Prügl, Elisabeth. 2015. «Neoliberalising Feminism.» New Political Economy 20(4): 614-631. DOI: https://doi.org/10.1080/13563467.2014.951614.

Reis, Josemira Silva. 2017. «Feminismo por hashtags: as potencialidades e riscostecidos pela rede.» Seminário Internacional Fazendo Gênero 11 \& $13^{\text {th }}$ Women's Worlds Congress (Anais Eletrônicos), Florianópolis, 1-13.

Rottenberg, Catherine. 2018. The Rise of Neoliberal Feminism. New York: Oxford University Press.

Sullivan, Katie Rose, e Helen Delaney. 2016. «A Femininity That 'Giveth and Taketh Away': The Prosperity Gospel and Postfeminism in the Neoliberal Economy.» Human Relations, 70(7): 836-859. DOI: https: / / doi.org/10.1177/0018726716676322

Teixeira, Jacqueline Moraes. 2012. «Corpo e sexualidade: os direitos reprodutivos na Igreja Universal do Reino de Deus.» Mandrágora 18(18): 53-80.

Teixeira, Jacqueline Moraes. 2014. «Mídia e performances de gênero na Igreja Universal: o Desafio Godllywood.» Religião e Sociedade 34(2): 232-256. 
Monise Martinez. Doutoranda em Estudos Feministas no Centro de Estudos Sociais da Universidade de Coimbra, com projeto de tese financiado pela Fundação para Ciência e Tecnologia (FCT). Mestre em Estudos Editoriais pela Universidade de Aveiro, Portugal. Bacharel em Letras pela Universidade de São Paulo, Brasil.

Endereço eletrônico: martinezmonise@gmail.com

Artigo recebido em 13 de julho e aceite para publicação em 7 de outubro de 2020. 